\title{
Responsibilities of Pregnant Women for on Going Pregnancy - Medical Aspects
}

\author{
RATKO MATIJEVIĆ \& KATJA ERJAVEC
}

\begin{abstract}
There are numerous factors known to affect the course of pregnancy and adversely impact perinatal mortality and morbidity. Some of them are avoidable and some are not. Avoidable factors can be either under responsibility of medical staff, health care systems and communities; or under responsibility of pregnant women. By modifying and changing their lifestyle, pregnant women can influence some avoidable factors and improve their pregnancy outcome. However, by ignoring them, they can cause potential damage to themselves and to their unborn child. There is no well defined responsibility for women concerning ways they influence their pregnancy outcome; they have a full right to make decisions about themselves and their unborn children, whether right or wrong. Good communication, education and understanding are essential when dealing with these issues.
\end{abstract}

KEYWORDS: - obstetrics - antenatal care - pregnant women • lifestyle habits

CORRESPONDENCE ADDRESS: Ratko Matijević, Ph.D., Professor, University Hospital Merkur, Department Of Obstetrics and Gynecology, Zajčeva ulica 19, HR-10000 Zagreb, email: rmatijev@mef.hr. Katja Erjavec, M.D., University Hospital Merkur, Department Of Obstetrics and Gynecology, Zajčeva ulica 19, HR-10000 Zagreb, email: katya.erjavec@gmail.com.

DOI 10.18690/24637955.9.2.121-130(2016)

ISSN 2463-7955 Print (C) 2016 University of Maribor Press

Available online at $\mathrm{http} / / /$ joournals.um.si. 


\section{Introduction}

Pregnancy and childbirth are generally normal and positive events. There are numerous factors known to affect the course and outcome of pregnancy and adversely impact maternal and fetal well-being as well as perinatal mortality and morbidity. Several maternal diseases appearing prior to pregnancy, some conditions that emerge either prior or during pregnancy, maternal age, body mass index (BMI), psychosocial status as well as lifestyle habits and many others are well known factors which have an impact on the course of pregnancy and determine pregnancy outcome. Some of the listed factors, such as maternal age, height, body shape or certain conditions are constant, genetically defined and non modifiable; while others, such as pre pregnancy weight, weight gain, diet and lifestyle habits are modifiable and can be altered in order to improve the course of pregnancy and minimize the risk of adverse outcome.

During the last decade there has been increasing focus on the rights of pregnant women during pregnancy and labour. Special laws have been passed on the workplace and employment rights of pregnant women, (European Union Law, 1992) comprehensive standards have been established on appropriate and complete antenatal care (European Board \& College of Obstetrics and Gynaecology, 2014), guidelines have been written on mother-baby friendly birthing facilities (International Federation of Gynecology and Obstetrics, 2015); all aiming for enhancing pregnant women's safety, health and life quality. The rights and needs of pregnant women are continuously being acknowledged and promoted with significant progress and increased public awareness observed in recent years (International Federation of Gynecology and Obstetrics, 2012).

On the other hand, very little is said about the responsibilities of pregnant women concerning factors they can personally modify and change in order to improve their pregnancy outcome. Lifestyle habits including alcohol consumption, cigarette smoking or illicit drug intake have indisputable adverse perinatal squeals both to the mother and her unborn child. Moreover, avoiding and not attending antenatal care or ignoring advice offered by health care professionals can have serious consequences to pregnancy outcome and can be viewed as a form of neglect to the unborn child. In these circumstances, the main issue is not the right or wrong of scientific arguments about this matter, placing physical autonomy of the pregnant woman on the first place.

Alcohol, smoking and illicit drugs

Alcohol is a potent teratogen that causes a broad spectrum of prenatal damage termed fetal alcohol spectrum disorders. Among these the most serious condition is fetal alcohol syndrome (FAS) characterized by growth restriction, facial abnormalities and central nervous system dysfunction. The minimum amount of alcohol required to produce adverse fetal consequences is unknown so most public 
health guidelines recommend total abstention (European Institute od Women's Health. Women and Alcohol in the EU, 2013).

Cigarette smoking during pregnancy, either active or passive, is linked to various complications including preterm birth, low birth weight, placental abruption or placenta previa and sudden infant death syndrome (SIDS), primarily by reducing uteroplacental blood flow and generating fetal hypoxia. Also, some of the substances of cigarette smoke are teratogens and certain birth defects such as oral facial abnormalities or cardiac anomalies have been reported to occur more frequently among infants of women who smoke (European Institute od Women's Health. Pregnancy and smoking, 2013). Passive smoking is potentially even worse than active. As with alcohol, there is no amount of cigarettes considered to be 'safe' during pregnancy, but effects are exaggerated by the number of cigarettes smoked.

Despite unequivocal downsides in alcohol consumption and cigarette smoking in pregnancy, estimates say around $10 \%$ of pregnant women drink alcohol during pregnancy and $10-14 \%$ of women smoke cigarettes while pregnant (and these estimates only include women who admit to drinking and/or smoking so actual numbers are probably even higher) (Tan et al., 2015; Euro Peristat, 2012). Both alcohol consumption and cigarette smoking are legal and women are free to smoke or drink, but what happens when these habits endanger the well-being of the unborn child? A recent case from 2014 from United Kingdom exemplifies this. A mother who inflicted lifelong damage on her child after drinking heavily during her pregnancy was ruled not guilty of crime, primarily because of the limits on the legal rights of unborn children who do not have a separate existence in law. In details, the offence of poisoning requires the victim to be "another person" while an unborn baby is a unique organism, but not a person. To the best of our knowledge, the legal aspects are similar in other European countries. However, when we allow people to choose to drink and to assume the responsibility of driving while under influence of alcohol, we prosecute them for drunk driving, killing or injuring someone by driving under such condition. Why should pregnancy exempt women from accountability for irresponsive and illegal behavior? This is one of many unanswered questions regarding similar matters. Advocates of bodily autonomy during pregnancy claim that women are asked to give up alcohol not because of the associated health risks but rather because of an insidious moralizing of women - pregnant women have a moral responsibility to lead a healthy lifestyle (Bristow, 2007).

The case with illicit drugs is somewhat different. It is well known that tobacco and alcohol use during pregnancy do have determinant effects on the unborn child. However, they are legal, while illicit drugs are not. According to data from the USA, at least $10 \%$ of fetuses are exposed to one or more illicit drugs, but data are scarce and limited. Cocaine is associated with serious maternal complications including myocardial damage and placental abruption, congenital abnormalities, 
fetal growth restriction and preterm birth, amphetamines are major teratogens causing fetal growth restriction and behavioural abnormalities and marijuana is linked to low birth weight and preterm birth (Cunningham, 2014).

As we know, in the USA, Tennessee is the only state where a woman can be prosecuted for using illegal drugs while pregnant (American Pregnancy Association, 2015). In Europe, to the best of our knowledge there is no such practice. Should we do something about it? In further decision making and eventually altering a law we should be very careful as charging a mother for willfully contributing to the death or injury of her unborn child can be seen by many as violation of her autonomy rights and as a possible step to interfering with abortion rights by conferring the status of personhood of the unborn child.

Appropriate antenatal care is believed to be one of the important contributors of reduction of maternal and fetal morbidity and mortality continuously observed during the past century. Many obstetrical and medical risk factors and complications are identifiable during antenatal care and many complications are treatable when noticed and diagnosed on time. Recent studies and pregnancy management policies are determining the significance of maternal compliance to offered antenatal care and how women's disregarding medical advice or recommendation and refusal for regular antenatal visits reflects on pregnancy outcome. Studies have shown that women receiving no antenatal care have a higher risk for preterm birth, stillbirth and neonatal death and a fivefold increased risk for maternal death (Cunningham, 2014). And yet, estimates report that up to $12 \%$ of American women receive inadequate perinatal care, and around $16 \%$ of mothers begin care only after the first 3 months of pregnancy (Martin et al., 2007). Data from the European Union countries are more encouraging, where care in the largest number of countries begins in the second or third trimester for only 4 and $7 \%$ of all women, while the percentage of women with no antenatal care at all ranges from 0 to $2.8 \%$ (European Perinatal Health Report, 2012). According to data from Croatian Institute of Public Health, around 5\% of women in Croatia have 5 or less antenatal visits during pregnancy (Croatian Institute for Public Health, 2016).

Knowing all the benefits of antenatal care it is difficult to understand why some women refuse to attend antenatal clinics. Lack of education and public awareness of the importance and advantages of antenatal care surely play a role, while low economic status is less likely to contribute as all European countries cover the cost of an antenatal care package. Medical staff is also partly to blame, since we are sometimes unsuccessful in communicating our message about the importance of antenatal care correctly and completely to our patients. 
There is a difference between antenatal care and other types of general medical care The wrong decision of the pregnant woman may not only affect her health but also the health and well-being of her unborn child. Although most pregnant women willingly accept potential risks to their health and body anatomy in order to optimise fetal outcome, occasionally some of them refuse treatment optimised for the benefit of the fetus. This is also known as "maternal fetal conflict" (Ludwig, 1998). With advancement of medical science and technology, the fetus has become able to live independently of its mother long before the due date. Thus, mother and fetus are no longer regarded as one entity, the so called "maternal-fetal dyad", but rather as two biologically connected patients. The two patients are defined and distinguished by two questions: when does life begin and when does the fetus become a person? However, there are no clear and uniform answers to these questions. This medical change in maternal fetal liaison has not been appropriately accompanied by advancement and change in legal science. The legal definition of life is "independent existence as an animate being" (Duhaime's Law Dictionary), but even though the fetus can often live independent to mother support, this does not imply it has legal rights as a person. This is illustrated in a legal case when a motor vehicle accident had caused a pregnant woman to deliver preterm in order to save the fetus. The baby was not born viable and when life support was removed a few hours later, the child died. The verdict for the driver who committed the accident was that he was not guilty of homicide, since there could be no homicide without a living human being the victim. The killing of an unborn child was not a homicide at common law for the reason that the fetus was not considered a person, it was necessary that the child be born alive and exist independently of its mother's body before it could be considered a person (People v. Selwa, 1995). Similarly, in Illinois, USA, charge of murder does not apply unless the child is killed after umbilical cord is cut and the full separation of the baby from the mother has occurred (The People of the state of Illinois v. Elizabeth Elhert, 2002).

\section{Refusal, denial and ignoring medical advice - medical staff view}

Refusal, denial and ignoring medical advice, management and/or treatment are some of the possible actions that may jeopardize pregnancy and influence pregnancy outcome by increasing maternal mortality and morbidity. These are accountable and considered as preventable factors and are under full responsibility of pregnant women who make such decisions. To medical staff, it is very difficult to understand the reasons for such behaviour. Even worse, such actions can be very frustrating, and can provoke reactions of medical staff which unnecessarily aggravate the situation. There is always an open question - how to deal with such issues and what to do? However, there is no right and uniform answer to this question and each case should be managed individually. 
If you encounter a patient, or in this case a pregnant woman that refuses, denies or ignores medical advice, management and/or treatment; to start with, it is important to ask yourself a question what is the reason for the refusal or denial? It is mandatory to be sure that proposed course of action and your suggestions represent the best of your medical knowledge and are the best option in the present situation. Be careful. In obstetrics, there are several actions and procedures that are common and have become a routine for decades but some of them have been challenged regarding their justifiable use in recent years. These are routine active management of labour, oxytocin use or amniotomy, the use of enema on hospital admission, shaving the perineum, routine episiotomies and many others. Interestingly, just these "challenged" procedures are most frequently refused in clinical practice. Therefore, it is mandatory to keep your knowledge up to date about the different management options and offer proper counselling to pregnant women helping them to make a proper decision.

If you are sure that you are right, meaning that your proposed management plan or course of action represents the best option for the pregnant woman, and if she still denies and/or refuses your proposal; be sure that you communicated your plans well and that she, and people around her, understand you well. The communication problem and misunderstanding or lack of understanding between medical staff and pregnant women are the commonest reasons of refusal of medical treatments. Use simple language, do not use medical terms, ask questions, have an open dialog, listen. By improving and adjusting your communication skills you will solve several problems of misunderstanding and refusal. Test yourself by asking someone else through a communication process (partner, family, colleague) did they understand you well and what they thought about your proposed plans and reasons for refusal. This may be helpful in two ways, either you will get someone neutral or someone from the 'patients team' on your side, or you will find out that your communication process was not successful and you have to repeat it. If refusal persists, look at the problem from the patient's perspective. Try to find reasons for refusal, as nearly always there is a reason present. Find out is this wanted pregnancy, is this refusal a reaction to some previous event, is there a financial, religious or cultural problem responsible for denial or refusal or something else. If you find a cause or reason, you may be able to act on it. If this also does not work, you should ask yourself a question whether your patient is capable of making a decision? Involve the partner, family, relatives and also other medical professionals i.e. psychiatrists in order to try to get the best way out from this situation and to find an option acceptable for your patient. It is mandatory that you eliminate your feelings and emotions, anger or disappointment, and that you go to the communication process with "cold head". Finally, keep your notes clear and precise, well document your proposed plans and explanation refused by the patient, make clear the possible consequences, ask your patient did they understand you well, offer them to ask questions and finally ask them to sign informed written refusal of proposed plans of action. To have someone witnessing from both sides is always helpful. 
One of the most frustrating refusals in obstetrics is the one of delivery by caesarean section, especially in cases when unborn child's life is at risk. During the last decade there has been an increasing rate of caesarean sections done worldwide and in some countries caesarean section rate account for almost $50 \%$ of all births (Luz et al., 2010). However, in recent years there is also a rising trend of denial and refusal of offered elective caesarean section delivery in developed world. It is clear that doctors performing an intervention on patients' bodies without their consent are working against the law. In the case of refusal of caesarean section delivery, especially if the indication for this delivery is fetal jeopardize, it can be difficult for medical professionals to keep calm and accept such a decision. However, in all cases where a treatment poses personal risk to the mother and her bodily integrity, a physician should honour a woman's right to refuse treatment! There is no punishment or guilt for the medical professionals if they are following patient's wishes (Nelson \& Millken, 1988).

The potential way out of this situation is by defining the right risk for the unborn child, to have clear evidence that proposed treatment (i.e. caesarean section) would help, to minimise the risk for the pregnant woman and finally to ask the ethical committee in charge to allow you to ask for a court order to perform action against pregnant woman's decision. Luckily, the need for such course of action is extremely rare and court orders to force treatment on pregnant women raise many ethical concerns. The American College of Obstetricians and Gynecologists clearly stated that obstetricians should refrain from performing procedures that are unwanted by pregnant women and that the use of court to resolve conflict regarding this matter is almost never warranted (Patient choice: maternal-fetal conflict, 1990).

Before giving up, ask yourself these questions:

1. Is there anything else I can do? Is there anything else someone else can do?

2. Are my explanations clear that everyone around me understood what I am doing and why I am doing this?

3. Is everything well documented and clear in the notes? Can someone not involved in the present case follow the whole course of action by reading the notes?

4. Have you reported the incident form to the responsible body (i.e. quality control management)?

\section{Conclusion}

There are numerous avoidable factors known to affect the course and outcome of pregnancy and adversely impact perinatal mortality and morbidity. By avoidable in this situation we mean that some of them are directly influenced by behaviour of pregnant women making them directly and indirectly responsible for adverse 
pregnancy outcome. By modifying and changing their lifestyle, pregnant women can influence pregnancy outcome but sticking with bad habits (i.e. by not attending regular antenatal care or by denying and refusing medical advice regarding management options and plans); pregnant women may cause potential damage to themselves and to their unborn child. There is no well defined responsibility for pregnant women regarding this matter despite the known relationship between their behaviour and bad pregnancy outcome, as "maternal fetal-dyad" is still giving the full right to pregnant women to make decision about herself and her unborn child. Good communication skills of medical staff and education of pregnant women with a lot of patience can be of use in order to solve the problem, as any forced intervention may adversely affect the relationship between pregnant women and medical staff.

\section{References}

American Pregnancy Association (2015) Using Illegal Drugs During Pregnancy, available at: http://americanpregnancy.org/pregnancy-health/illegal-drugs-during-pregnancy/ (August 28, 2016).

Bristow J. (2007) Rule 3: Pregnancy does not damage your child. Spiked, available at: http://www.spiked-online.com/newsite/article/3422\#.V8VVpmWS3Us (August 30, 2016.

Croatian Institute for Public Health (2016) Croatian Health Service Yearbook 2015. Zagreb, available at: http://www.hzjz.hr/wpcontent/uploads/2016/05/Ljetopis_2015.pdf (August 28, 2016).

European Board \& College of Obstetrics and Gynaecology (2014) Standards of care for women's health in Europe, available at: http://www.ebcog.org/index.php?Itemid=178\&id=20\&option=com_content\&view=arti cle (August 28, 2016).

European Institute of Women's Health (2013) Women and smoking in the EU, available at: http://eurohealth.ie/2013/05/31/women-and-smoking-in-the-eu/ (August 28, 2016).

European Institute of Women's Health (2013a) Women and Alcohol in the EU, available at: http://eurohealth.ie/wp-content/uploads/2013/07/Alcohol_PB_3June.pdf (August 28, 2016).

European Union Law (1992) Council Directive 92/85/EEC on the introduction of measures to encourage improvements in the safety and health at work of pregnant workers and workers who have recently given birth or are breastfeeding, available at: http://eurlex.europa.eu/legal-content/en/ALL/?uri=CELEX:31992L0085 (August 28, 2016.

Euro Peristat (2012) The European Perinatal Health Report 2010, available at: http://www.europeristat.com/reports/european-perinatal-health-report-2010.html. (August 28, 2016).

Gibbons, L., Belizán, J. M., Lauer, J.,A., Betrán, A. P., Merialdi, M. \& Althabe, F. (2010) World Health Report Background paper, No 30. The Global Numbers and Costs of Additionally Needed and Unnecessary Caesarean Sections Performed per Year: Overuse as a Barrier to Universal Coverage, available at http://www.who.int/healthsystems/topics/financing/healthreport/30C-sectioncosts.pdf (August 27, 2016). 
International Federation of Gynecology and Obstetrics (FIGO) (2012) Ethical Issues in Obstetrics and Gynecology by the FIGO Committee for the Study of Ethical Aspects of Human Reproduction and Women's Health, available at: http://www.figo.org/sites/default/files/uploads/wgpublications/ethics/English\%20Ethical\%20Issues\%20in\%20Obstetrics\%20and\%20Gyn ecology.pdf (August 30, 2016).

International Federation of Gynecology and Obstetrics; International Confederation of Midwives; White Ribbon Alliance; International Pediatric Association; World Health Organization; International Federation of Gynecology and Obstetrics (2015) Motherbaby friendly birthing facilities, International Journal of Gynecology and Obstetrics, 128(2), pp. 93-94, doi: 10.1016/j.ijgo.2014.11.002.

Ludwig, M. (1998) Maternal fetal conflict (Washington D.C.: University of Washington), available at https://depts.washington.edu/bioethx/topics/matern.html (August 27, 2016).

Martin, J. A., Hamilton, B. E., Sutton, P. D., Ventura, S. J., Menacker, F., Kirmeyer, S. Munson, M. L. \& Centers for Disease Control and Prevention National Center for Health Statistics National Vital Statistics System (2007) Births: final data for 2005, National Vital Statistics Reports, 56(6), pp. 1-103.

Nelson, L. J. \& Milliken, N. (1988) Compelled medical treatment of pregnant women: life, liberty, and law in conflict, JAMA, 259(7), pp. 1060-1066.

People v. Selwa. (1995). 214 Mich. App. 451, 543 N.W.2d 321, available at: https://scholar.google.ca/scholar_case?case $=4669809070735911573 \& q=543+n w+2 d+3$ 21\&hl=en\&as_sdt=2006 (August 28, 2016).

Tan, C. H., Denny, C. H., Cheal, N. E., Sniezek, J. E. \& Kanny, D. (2015) Alcohol use and binge drinking among women of childbearing age - United States, 2011-2013, MMWR Morbidity and Mortality Weekly Report, 64(37), pp. 1042-1046.

The American College of Obstetricians and Gynecologists (1990) Patient choice: maternalfetal conflict. Committee opinion from the Committee on Ethics, Women's Health Issues, 1(1), pp. 13-15, doi: 10.1016/S1049-3867(05)80006-4.

The People of the state of Illinois v. Elizabeth Elhert. Document No 1-00.0273. (Illinois Appellate Court 2002), Available at http://www.illinoiscourts.gov/opinions/appellatecourt/2002/1stdistrict/november/html/1 000273.htm (August 27, 2016).

Cunningham, F. G. (eds.) (2014) Williams Obstetrics, 24th ed. (New York: Mc Graw Hill Education). 